\title{
Location of the retinoblastoma susceptibility gene(s) and the human esterase D locus
}

\author{
PATRICIA WARD*, SEYMOUR PACKMAN*, WILLIAM LOUGHMAN*, \\ MARYELLEN SPARKES $\dagger$, ROBERT SPARKES $\dagger$, ANN McMAHON*, \\ TERESA GREGORY*, AND ARTHUR ABLIN
}

From the Divisions of Genetics * and Hematology-Oncology $\ddagger$, Department of Pediatrics, University of California, San Francisco; and †the Departments of Medicine, Pediatrics, and Psychiatry, University of California School of Medicine, Los Angeles, USA.

SUMMARY Retinoblastoma occurs with increased frequency in children born with a deletion of the $\frac{6}{N}$ long arm of chromosome 13. Recent reviews have noted that the region 13q14 is consistently deleted 윽 in documented cases. Prometaphase and late prophase banding allowed Yunis and Ramsay to $\rightarrow$ determine that a deletion in one patient included the sub-bands q14.12, q14.13, and q14.2, and a portion of $\mathrm{q} 14 \cdot 11$ and $\mathrm{q} 14 \cdot 3$. We report the results of similar cytogenetic techniques applied in the case of a 26 month old Caucasian female with unilateral retinoblastoma, moderate developmental $\vec{\emptyset}$

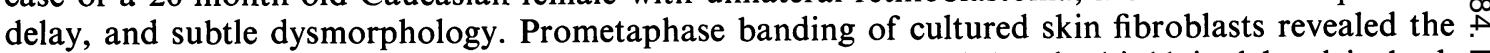
karyotype: $\operatorname{mos} 46, \mathrm{XX} / 46, \mathrm{XX}, \operatorname{del}(13)(\mathrm{q} 13 \cdot 1 \mathrm{q} 14 \cdot 11)$. Only the sub-band $\mathrm{q} 14 \cdot 11$ is deleted in both our patient and that of Yunis and Ramsay. The results are consistent with the localisation of the retinoblastoma susceptibility gene(s) in the sub-band $13 \mathrm{q} 14 \cdot 11$.

Electrophoretic analysis and activity assays of red blood cell esterase D are consistent with hemizygous expression of that marker in our proband. Comparison with published esterase D $\Omega$ analyses in families with retinoblastoma permits the assignment of the esterase D locus to that same sub-band, $13 \mathrm{q} 14 \cdot 11$.

Retinoblastoma is a retinal tumour of early childhood, with an estimated incidence of 1 in 20000 live births. ${ }^{2}$ Most cases are sporadic, without a definable mode of inheritance. However, there are two types of retinoblastoma of genetic aetiology: (1) a predisposition to develop the tumour based on an autosomal dominant mode of inheritance with incomplete penetrance; and (2) a predisposition to develop the tumour in persons with a deletion of the long arm of chromosome 13 . Recent reviews ${ }^{13}$ of $13 q$ deletion cases have noted that the region $13 q 14$ is consistently absent. Prometaphase and late prophase banding techniques allowed Yunis and Ramsay ${ }^{1}$ to determine that a deletion in one patient included the sub-bands $\mathrm{q} 14 \cdot 12$, q14.13, and $\mathrm{q} 14 \cdot 2$, and a portion of $q 14 \cdot 11$ and $q 14 \cdot 3$. We report the results of cytogenetic studies of a patient which permit further localisation of the retinoblastoma susceptibility region.

Grant support: USPHS-NIH grants GM28838 and AM 25884, and a grant from the March of Dimes Birth Defects Foundation.

Received for publication 29 September 1982.

Accepted for publication 15 August 1983.
Analyses of electrophoretic polymorphisms and variations in activity of esterase $\mathbf{D}$ have permitted assignment of the esterase D locus to the 13q14 region. ${ }^{4}$ We report the application of this approach 8 in our patient and the evidence for a more precise assignment for the human esterase $D$ locus.

\section{Case report}

The proband is a 26 month old Caucasian female 0 with unilateral retinoblastoma. She was the third $N$ child born to a 26 year old mother and a 29 year old $\underset{\omega}{N}$ father after a 40 week pregnancy remarkable for third trimester maternal weight loss and decreased fetal $O$ activity. Delivery was complicated by a relatively large head circumference (70th centile). Birth weight $\stackrel{\mathscr{S}}{\rightarrow}$ was $2950 \mathrm{~g}$ (25th centile). During the first 5 months 0 of life there was a history of poor feeding, irritability,

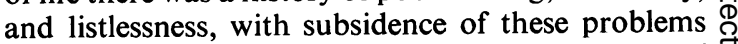
after 5 months. At the age of 22 months the sclera of $\mathbb{\otimes}$ her right eye became discoloured. The diagnosis of retinoblastoma was made and the right eye was 
enucleated. Retinoblastoma was confirmed histologically in the enucleated eye. No radiation or chemotherapy was undertaken. At that time, the left eye showed no indication of tumour formation, and currently (6 years) it remains uninvolved. No other family members have retinoblastoma.

At the age of 26 months her height $(80.5 \mathrm{~cm})$ and weight $(10.4 \mathrm{~kg})$ were both slightly below the 10 th centile with a head circumference $(49 \mathrm{~cm})$ at the 60 th centile. Craniofacial anomalies included prominent forehead, epicanthic folds, and a slightly flattened maxilla (fig 1). There was bilateral fifth finger clinodactyly, bilateral overlapping of the middle toes, and mild joint laxity. The proband was moderately developmentally delayed, most markedly in her speech. On formal testing (aged $4 \frac{1}{2}$ years) she achieved a mental age of $2 \frac{3}{4}$ years (Stanford Binet Intelligence Scale).

\section{Materials and methods}

Peripheral blood cultures were established in commercial chromosome kits (Difco, Detroit),

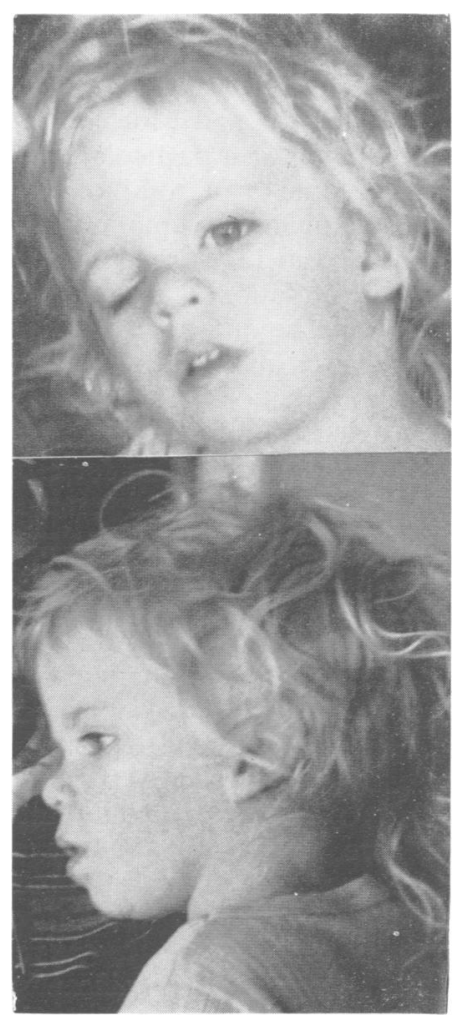

FIG 1 The proband aged 26 months. according to the manufacturer's instructions, but employing the culture modification for high resolution analysis of chromosomes of Yunis. ${ }^{5}$ At 72 hours of culture, a cell cycle $S$ period block was induced by adding Amethopterin (Sigma Chemical Company, St Louis) to $0 \cdot 1 \mu \mathrm{mol} / 1$ final concentration. Seventeen hours later thymidine was added to $0.02 \mathrm{mmol} / \mathrm{l}$ final concentration, releasing the induced $S$ period block. After 2 hours' additional incubation, colchicine was added to a final concentration of $0.07 \mu \mathrm{g} / \mathrm{ml}$. The cell cultures were harvested in the usual manner 10 minutes later and microscope slides were prepared. These were heated for 1 hour on a $60^{\circ} \mathrm{C}$ slide warmer, then stained in trypsin-Giemsa solution (GTG). Chromosomes were examined under the microscope at $\times 800$ and $\times 1250$, and on photographs at $\times 2000$ and $\times 4000$ final enlargement. The nomenclature throughout the present report is that of ISCN (1981). ${ }^{6}$

Electrophoresis of esterase $\mathrm{D}$ was performed according to a modification of the method of Hopkinson et al. ${ }^{7}$ For esterase $\mathrm{D}$ activity, the fluorescent method described by Sparkes et $a l^{8}$ was used.

\section{Results}

Metaphase banding performed on the proband's peripheral lymphocytes showed mosaicism for an interstitial deletion of 13q: $46, \mathrm{XX} / 46, \mathrm{XX}, \operatorname{del}(13)$ (q12q14). Of 60 cells, 56 showed the deletion. The proband's parents and sibs are cytogenetically normal, based on results obtained by the same method.

To define the deleted region more precisely, the proband's cultured skin fibroblasts were studied with prometaphase banding. These results were analysed based on ideograms of GTA banded human prometaphase chromosomes ${ }^{6}$ with the following assessment: 46,XX/46,XX, del(13) (q13.1q14.11) (fig 2). The percentage mosaicism was not calculated in fibroblast preparations.

Red blood cell esterase D activities were in the normal range ${ }^{4}$ for the mother (68.6 units) and father (76 units) of our patient. The proband's activity of 38.9 units was 51 to $57 \%$ that of her parents. The electrophoretic phenotype of all three family members was type 1-1. Reduced activity on electrophoresis in the case of the proband, taken together with the quantitative assay data, permitted the final designation of the proband's electrophoretic pattern as $1-0.4$

\section{Discussion}

It is important to note that our proband exhibited 

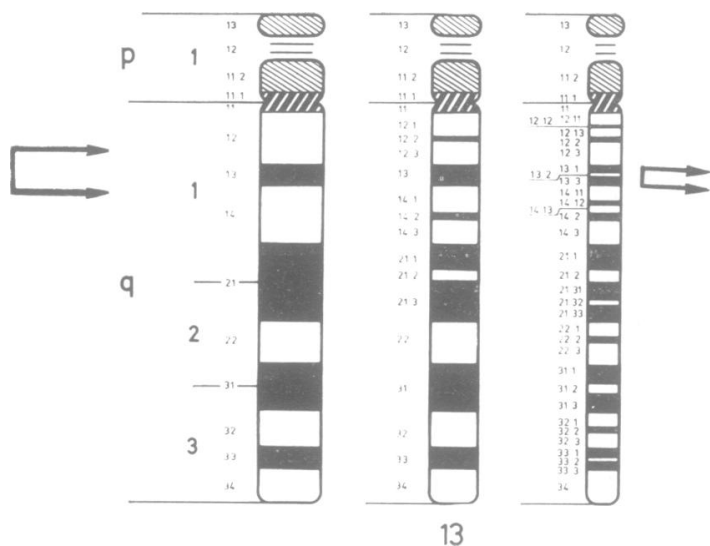

FIG 2 Normal and deleted chromosomes 13 studied with prometaphase banding. Ideogram is froin reference 6.

subtle dysmorphic features, including only a few of the characteristic findings in reported cases with larger deletions. ${ }^{129}$ Because of this, chromosomal analysis might not have been performed without the clinical diagnosis of retinoblastoma. In numerous reported cases which have undergone karyotyping since the seminal study of Lele et al, ${ }^{10}$ both metaphase $^{911-23}$ and prometaphase ${ }^{19}$ banding techniques have been used. Unilateral ${ }^{42425}$ and bilateral ${ }^{25}$ retinoblastoma have been reported with mosaicism for deletions of chromosome 13. Based on accumulated cytogenetic evidence, Francke ${ }^{3}$ and Yunis and Ramsay ${ }^{1}$ noted the consistent deletion of band 13q14.

A comparison of our results with case 2 of Yunis and Ramsay ${ }^{1}$ (a small interstitial deletion of $13 q$ associated with retinoblastoma) is instructive. The proband of Yunis and Ramsay shows a deletion involving all of sub-bands $13 \mathrm{q} 14 \cdot 12$, $13 q 14 \cdot 13$, and $13 q 14 \cdot 2$ and adjacent portions of $13 q 14 \cdot 11$ and $13 q 14 \cdot 3$. Our proband's deletion spans the sub-bands $13 \mathrm{q} 13 \cdot 1$ to $13 \mathrm{q} 14 \cdot 11$, leaving intact the sub-bands $13 q 14 \cdot 12,13 q 14 \cdot 13,13 q 14 \cdot 2$, and $13 \mathrm{q} 14 \cdot 3$. The region $13 \mathrm{q} 14 \cdot 11$ remains as the only sub-band deleted in both our patient and the proband of Yunis and Ramsay. ${ }^{1}$

The comparative findings are consistent with localisation of the retinoblastoma susceptibility gene(s) to the sub-band 13q14.11. The results are also consistent with previous attempts at such localisation, except for two reports, ${ }^{22} 26$ each involving translocations with breakpoints at $13 \mathrm{q} 12$ and intact $13 \mathrm{q} 14$ bands. Davison et $\mathrm{l}^{22}$ suggest that a second genetic element may be influencing the susceptibility to retinoblastoma in their proband. Nichols $e t a^{26}$ reported studies of a proband with retinoblastoma and a $13 q ; X p$ translocation, pre- $\frac{T}{2}$ viously reported by Cross et al. ${ }^{18}$ The report of Nichols et $a^{26}$ suggests that the $13 q 14$ band remained intact in the same segment translocated to $\mathrm{Xp}$, but that inactivation of the derivative chromosome predisposed the patient to retinoblastoma. This interpretation is supported by analysis of this patient's cells when fused to mouse cells. ${ }^{27}$

In related studies of familial (dominant) retinoblastoma, Knight et $a l^{28}$ and Morten et $a l^{29}$ found discordant segregation of a particular chromosome 13 and retinoblastoma in a total of six of seven families. The fundamental assumption, namely that the deleted sub-band in 13q- retinoblastoma is also the location of the mutation in autosomal dominant retinoblastoma, may be questioned on the basis of such studies. However, meiotic crossing over with a high recombination fraction between the centromere and the q14 locus, as proposed by the authors, ${ }^{28}{ }^{29}$ may be an alternative explanation for their results. Such a proposal is supported by high recombination frequency estimates independently derived from chiasma distribution data along the long arm of chromosome $13 .^{30}$

It has previously been demonstrated that human esterase D, a polymorphic genetic marker, maps in the same 13q14 region as the locus for predisposition to retinoblastoma. ${ }^{4}$ Important evidence for such close linkage came from studies of the expression of esterase $\mathbf{D}$ in patients with retinoblastoma and $\stackrel{\mathcal{C}}{\rightarrow}$ deletions of chromosome 13. That approach is 7 extended in the present work. Both the half-parental activity and the 1-0 electrophoretic pattern of esterase $D$ are consistent with hemizygous expression of esterase D in our proband. Significantly, esterase $D$ activity in the critical proband (case 2) of Yunis 
and Ramsay ${ }^{1}$ was also half that of the parents (family 4 of reference 4 ). Accordingly, as the region $13 \mathrm{q} 14 \cdot 11$ is the only sub-band deleted in both our patient and the Yunis and Ramsay proband, we contend that the esterase $\mathrm{D}$ locus is indeed quite closely linked to the retinoblastoma susceptibility locus in sub-band $13 \mathrm{q} 14 \cdot 11$. This contention is supported by recent family studies demonstrating close linkage of inherited retinoblastoma susceptibility and esterase D. ${ }^{31}$ Such close linkage should prove valuable for genetic counselling and antenatal diagnosis, and in studies of familial retinoblastoma segregating as a Mendelian trait.

We are most grateful to Dr Steven Schonberg of the Division of Genetics, Department of Pediatrics (University of California, San Francisco), for invaluable discussions and assistance during the course of this work. We should also like to thank Ms Beverly Cubbage for her excellent and tireless editorial assistance in the preparation of this manuscript.

\section{References}

1 Yunis JJ, Ramsay N. Retinoblastoma and subband deletion of chromosome 13. Am J Dis Child 1978;132: 161-3.

2 Francois J, DeBie S, Matton-Van Leuven MT. The Costenbader Memorial Lecture. Genesis and genetics of retinoblastoma. J Pediatr Ophthalmol 1979;16:85-100.

3 Francke U. Retinoblastoma and chromosome 13. Cytogenet Cell Genet 1976;16:131-4.

4 Sparkes RS, Sparkes MC, Wilson MG, et al. Regional assignment of genes for human esterase D and retinoblastoma to chromosome band 13q14. Science 1980;208: 1042-4.

5 Yunis JJ. High resolution of human chromosomes. Science 1976;191:1268-70.

6 ISCN (1981). An international system for human cytogenetic nomenclature: high-resolution banding. Birth Defects 1981 ;XVII:No 5.

7 Hopkinson DA, Mestriner MA, Cortner J, Harris H. Esterase D: a new human polymorphism. Ann Hum Genet 1973;37:119-37.

8 Sparkes RS, Targum S, Gershon E, Sensabaugh GF, Sparkes MC, Crist M. Evidence for a null allele at the esterase D (EC 3.1.1.1) locus. Hum Genet 1979;46:319-23.

9 Weichselbaum RR, Zabov ZN, Albert DM, Friedman AH, Nove J, Little JB. New findings in the chromosome 13 long arm deletion syndrome and retinoblastoma Opthalmol AAO 1979;86:1191-8.

10 Lele KP, Penrose LS, Stallard HB. Chromosome deletion in a case of retinoblastoma. Ann Hum Genet 1963;27: $171-4$.

11 Wilson MG, Towner JW, Fujimoto A. Retinoblastoma and D-chromosome deletions. Am J Hum Genet 1973; 25:57-61.

12 Orye E, Delbeke MJ, Vandenabeele B. Retinoblastoma and long arm deletion of chromosome 13. Attempts to define the deleted segment. Clin Genet 1974;5:457-64.

13 O'Grady RB, Rothstein TB, Romano PE. D-group deletion syndromes and retinoblastoma. Am J Ophthalmol $1974 ; 77: 40-5$.
14 Howard RO, Breg WR, Albert DM, Lesser RL. Retinoblastoma and chromosome abnormality. Partial deletion of the long arm of chromosome 13. Arch Ophthalmol 1974;92:490-3.

15 Ozawa H, Tanaka Y. Retinoblastoma and D-chromosome (13) deletions. Rinsho Ganka (Jpn J Clin Ophthalmol) $1975 ; 29: 253-9$.

16 Knudson AG, Meadows AT, Nichols WW, Hill R. Chromosomal deletion and retinoblastoma. $N$ Engl $J$ Med 1976;295:1120-3.

17 Wilson M, Ebbin AJ, Towner JW, Spencer WH. Chromosomal abnormalities in patients with retinoblastoma. Am J Hum Genet 1975;27:95A.

18 Cross HE, Hansen RC, Morrow G, Davis JR. Retinoblastoma in a patient with a $13 \mathrm{qXp}$ translocation. $A m \mathrm{~J}$ Ophthalmol 1977;84:548-54.

19 Riccardi VM, Hittner HM, Francke U, et al. Partial triplication and deletion of $13 \mathrm{q}$ : study of a family presenting with bilateral retinoblastomas. Clin Genet 1979;15:332-45.

20 Sparkes RS, Muller H, Klisak I. Retinoblastoma with $13 q$ - chromosomal deletion associated with maternal paracentric inversion of 13q. Science 1979;22:106-7.

21 Petit P, Fryns JP. Interstitial deletion of $13 q$ associated with retinoblastoma and congenital malformations. Ann Genet (Paris) 1979;22:106-7.

${ }^{22}$ Davison EV, Gibbons B, Aherne GES, Roberts DF. Chromosomes in retinoblastoma patients. Clin Genet 1979;15:505-8.

${ }^{23}$ Hilda T, Kinoshita Y, Matsumoto R, Suzaki N, Tanaka $H$. Bilateral retinoblastoma with a $13 \mathrm{qXp}$ translocation. J Pediatr Ophthalmol 1980;17:144-6.

24 Orye E, Benoit Y, Coppieters R, et al. A case of retinoblastoma associated with histiocytosis-X and mosaicism of a deleted D-group chromosome (13q14-q31). Clin Genet 1982;22:37-9.

25 Motegi T. High rate of detection of $13 q 14$ deletion mosaicism among retinoblastoma patients (using more extensive methods). Hum Genet 1982;61:95-7.

26 Nichols WW, Miller RC, Sobel M, et al. Further observations on a $13 \mathrm{qXp}$ translocation associated with retinoblastoma. Am J Ophthalmol 1980;89:621-7.

27 Mohandas T, Sparkes RS, Shapiro JF. Genetic evidence for the inactivation of a human autosomal locus attached to an inactive X chromosome. Am J Hum Genet 1982;34: $811-7$.

28 Knight LA, Gardner HA, Gallie BL. Familial retinoblastoma: segregation of chromosome 13 in four families. Am J Hum Genet 1980;32:194-201.

29 Morten JEN, Harnden DG, Bundey S. Family studies on the chromosomal location of the retinoblastoma gene (Rb-1). J Med Genet 1982;19:120-4.

3u Palmer RW, Hultén MA. Chiasma derived genetic maps and recombination fractions: chromosome 13 with reference to the proposed $13 \mathrm{q} 14$ retinoblastoma locus. $J$ Med Genet 1982;19:125-9.

${ }^{31}$ Sparkes RS, Murphree AL, Lingua RW, et al. Gene for hereditary retinoblastoma assigned to human chromosome 13 by linkage to esterase D. Science $1983 ; 219$ :971-3.

Correspondence and requests for reprints to Dr Seymour Packman, Division of Genetics, Department of Pediatrics, University of California, San Francisco, California 94143, USA. 